\title{
Quality of Life in Students From Four States of Mexico
}

\author{
Julio Cu Farfán López ${ }^{1}$, Jesús Alberto García García ${ }^{1}$, Yolanda Oliva Peña ${ }^{2} \&$ Gabriela Morán Delgado ${ }^{1}$ \\ ${ }^{1}$ Universidad Autónoma de Coahuila, Mexico \\ ${ }^{2}$ Universidad Autónoma de Yucatán, Mexico \\ Correspondence: Julio Cu Farfán López, Universidad Autónoma de Coahuila, Mexico.
}

Received: June 1, 2019

doi:10.5430/irhe.v4n2p45
Accepted: June 18, 2019

Online Published: June 30, 2019

URL: https://doi.org/10.5430/irhe.v4n2p45

\begin{abstract}
The objective of this work was to know the Quality of Life of young people of four states of Mexico with very marked cultural and geographical characteristics. To achieve the objective, the GENCAT Scale was used, proposed by Verdugo, Arias and others (2009) in which it is based on 8 sub scales: Emotional well-being, Interpersonal relationships, Material well-being, Personal development, Physical well-being, Self-determination, Social inclusion and Human rights. The sample was selected from a non-probabilistic sample of 620 young people. The instrument was validated with an item analysis in which it was obtained in Cronbach's alpha of 0.92. A comparative gender study was carried out and significant differences were found with the $\mathrm{T}$ test in four of the sub scales. It is concluded that young people perceive two spheres in their quality of life: the first from the personal factors is perceived very low, while the second, from the social or external factors is perceived with very high values. That is, when assessing the quality of life, young people are depersonalized, but with a high level of support from their context.
\end{abstract}

Keywords: quality of life, social factors, individual factors, university, GENCAT scale, Mexico

\section{Introduction}

\subsection{Quality of Life as a Contract}

The Quality of Life (QL) is a multifactorial construct that searches to measure reliably the objective and subjective dimensions about the personal or general perception of life.

It can be observed two dimensions on the QL: the objective dimension that has concrete indicators. The other dimension is the subjective perception from the people about themselves and their context. This two dimensions in four contexts: health (physical, psychological and emotional), family, social and the access of a quality education (Shaw, 1977; Hornquist, 1982, Calman, 1984; Oppong, Ironside y Kennedy (1988); Urzúa y Caqueo-Urízar, 2012).

Ardila (2003) \& Morales (2013) quoted by Guadarrama, Hernández, Veytia y Márquez (2014), define the QL as a state of general satisfaction derivate from their potentialities and the combination of objective and subjective aspects that are based on five principal dominions: physical wellness, material wellness, social wellness, development-activity and emotional wellness.

The quality of life is defined as the global satisfaction perceived and the satisfaction inside a series of key dominions with special emphasis on wellness (Hörnquist, 1990).

Guadarrama et al. (2014) conclude that the quality of life is a concept that is defined from the interaction of multiple factors; like age, sex, needs, satisfaction, the subject's perception of himself and the contexts where it is develop, the potentialities that one can develop, the practice of norms that express moral and the context where a person lives. Where wellness and satisfaction can be found.

The concept of quality of life can be used to represent the wellness of a community, if there is quality of life in an improvement community, it can be inferred as a progress population, and this is, that in the community, the wellness of their members has been increased.

On the search of the creation of instruments that measure the QL, Verdugo et al. (2009), propose the GENCAT scale and set as an objective to ensure, in Cataluna, Spain, the continuous improve of the services that offer to the citizenship, on the line to achieve some more personalizing and adequate services to their needs and actual and future requirements. 
The GENCAT scale is based on a multidimensional model in which exist eight dimensions or domains that when are taking together make the concept of Quality of life. We understand the basic dimensions of the quality of life as "the set of factors that compose the personal wellness", and their central indicators as "perceptions, specific conducts or conditions of the dimensions of the quality of life that reflex the wellness of a person" Verdugo, Arias, Gómez y Schalock (2009).

Verdugo et al. (2009), mention that the quality of life is understood as a multidimensional concept, composed by the same dimensions for all people, and it is influenced by environmental and personal factors, as well as their interaction, and it improves through the self-determination, the resources, inclusion and life goals.

\subsection{Quality of Life on Young Mexicans}

The different crisis on Mexico, have been pausing the individual and social development that was hoped. The geographic diversity of the Mexican Republic tight the development in some regions and improve others. In other words, there are different Mexico(s) inside the same Mexican territory. In Mexico ¿Has been any improvement on quality of life aspects?

Public politics in Mexico have given a spin on the assistance, because it is used as a political promotion. Likewise, in these social assistance programs, to support vulnerable groups, to attack poor, do they really serve to improve the QL of Mexicans?

There are big quantities of young people in Mexico, above any other age groups, and in a way that can sound contradictory, a few have the opportunity to assist to collage. The few privileged on studying a professional career have a latent risk to abandon their studies by the lack of economic resources, principally. In other words, the QL of students of professional level is not the one we have expected from more than fifty years ago.

Mexico is placed as the fifth country with the high number of young people between 15 and 29 years old that don't have a job, don't study and neither have training with the 22.1\% (OCDE, 2016). The unemployment rate is of $6.9 \%$ on the group of 15 to 19 years, and in the group of 20 to 24 is of 6.5\% (CONEVAL, 2012).

In Mexico (about the QL) findings in the states of Sonora and Oaxaca have been compared to the provinces of the United States and Canada. This investigation show social and health doubts contrasted with development countries related to the socioeconomically level and the measurement of quality of life (Tuesca, 2005).

González \& Landero (2007) say that in the north, university people of Mexico, have presented a correlation between the emotional fatigue with anxiety, stress and self-esteem, just as how was expected, the correlations were significant and just with the self-esteem is negative.

\subsection{Quality of Life Between Men and Women}

Some investigations have been realized from the decade of the fifties to the actual, where the sex variable is analyzed to know if there are differences on the perception of men vs women, in relation to their quality of life: the results are so diverse, because some articles do perceive differences and others don't.

The quality of life analysis, where have got differences that highlight in favor of the women in subjective wellness, emotion expression, and are less happy; also there are differences observed between the physical and emotional wellness. (Urzúa y Mercado, 2008; Yasuko, Romano, García y Félix (2005); Tarazona, 2005; Cherepanov, 2010; Li et al. (2010).

On the studies where there haven't found any differences between men and women, just perceive differences but not significant between the studied variables. (Leelakilthanit \& Day, 1992; Castellón \& Romero, 2004; Bryant \& Vernoff, 1984 in Yasuko et al. 2006; Cherepanov, Palta, Fryback \& Robert, 2010).

\section{Methods}

This study was realized with a quantitative design, synchronic on 620 students (30.3\% of men and $69.7 \%$ of women) of university levels on four states from the Mexican Republic: Chihuahua, Durango, Coahuila and Estado de México. A deterministic sample was used and applied during a month through written questionnaires.

The instrument that was used was the GENCAT scale, the authors Verdugo et al. (2009) validated by the University Institute of Community Integration from the Salamanca, Spain University.

The GENCAT measures the quality of life evaluated throught 69 items, distrbuted in eight subscales that correspond to the dimensions of the quality of life model (Schalock y Verdugo, 2009): Emotional wellness, interpersonal relationships, material wellness, personal development, physical wellness, self-determination, social inclusion and human rights. 
To know about the relibility of the instrument in Mexico, an analysis was made through the items to know the Cronbach's alpha that determine the reliability of each subscale and of the questions in a joint way.

The internal consistence method based on the Cronbach's alpha allows to estimate the reliability of the instrument of measurement through a set of items that are hope to measure the same construct or theoretical dimension

As general criteria, George y Mallery (2002) suggest the next recommendations to evaluate the Cronbach's alpha coefficient:

$\begin{array}{ll}\text { Alpha's coefficient }>.9 & \text { Is excelent } \\ \text { Alpha's coefficient }>.8 & \text { Is good } \\ \text { Alpha's coefficient }>.7 & \text { Is aceptable } \\ \text { Alpha's coefficient }>.6 & \text { Is questionable } \\ \text { Alpha's coefficient }>.5 & \text { Is poor } \\ \text { Alpha's coefficient }<.5 & \text { Is unacceptable }\end{array}$

The item analysis got a Cronbach's alpha of $0.92 \%$ which, according to the indicators is excellent. After there were proceed to generate the summary of each one of the eight subscales according to the procedure described by Schalock. It was realized a media analysis on the subscales to know major or minor quantitative presence of the subscales between themselves. The population was stratified in two groups: men and women to show the perception on quality of life is different between both groups. This was realized through the $\mathrm{T}$ test for independent samples with the SPSS program.

\section{Results}

Table 1. Validation of the 8 subscales from the Cronbach's alpha

\begin{tabular}{|c|c|c|}
\hline & Ítems & Alpha Cronbach \\
\hline Emotional wellness (EW) & 8 & 0.792 \\
\hline Interpersonal relationships (IR) & 10 & 0.728 \\
\hline Material wellness (MW) & 8 & 0.617 \\
\hline Personal Development (PD) & 8 & 0.626 \\
\hline Physical wellness (PW) & 8 & 0.466 \\
\hline Self-determination (SD) & 9 & 0.721 \\
\hline Social Inclusion (SI) & 8 & 0.588 \\
\hline Human Rights (HR) & 10 & 0.748 \\
\hline
\end{tabular}

Realizing the item analysis, was observed that the eight subscales of the physical wellness (.466), Social inclusion (.588), Material wellness (.617) and Personal development (.626), present between a poor and a questionable reliability. The others four subscales: Self-determination (.721), Interpersonal relationships (.728), Human rights (.748) and Emotional wellness (.792), present an acceptable reliability. Making the analysis of the 69 items an excellent Cronbach's alpha was achieved (.92) which the internal consistency approves the instrument. 
Table 2. Descriptive statistic on the summatories of the 8 subscales

\begin{tabular}{lccc}
\hline Summatories of the subscales & Media & SD & Variance \\
\hline Emotional wellness (EW) & 25 & 2.69 & 7.24 \\
Interpersonal relationships (IR) & 25.15 & 2.74 & 7.49 \\
Material wellness (MW) & 25.5 & 3.03 & 9.22 \\
Personal Development (PD) & 25.5 & 2.48 & 6.16 \\
Physical wellness (PW) & 26.19 & 2.91 & 8.52 \\
Self-determination (SD) & 31.03 & 3.62 & 13.14 \\
Social Inclusion (SI)* & 31.45 & 3.02 & 9.14 \\
Human Rights (HR)* & 32.01 & 3.3 & 10.89 \\
\hline
\end{tabular}

SD 3.08, SLN: 30.8 , ILN: 24.65

This last table shows the descriptive results from the sumatories of the 8 subscales, the mead of medias was obtained (27.73) to highlight which subscales are inside the limits of normality (at least one sigma) and which were above it; Highlighting the next subscales; Interpersonal Relationships (IR), Self-determination (SD) and Human Rights (HR) are above the normality ranges. The other five are located inside the limits of normality.

This indicates that the quality of life is perceived normal in Physical Wellness (PW), Emotional Wellness (EW), Social Inclusion (SI), Personal Development (PD), Material Wellness (MW) and Interpersonal Relationships (IR), but the self-determination and human rights are perceived very high, above the normality.

Table 3. $\mathrm{T}$ test for independent samples of men vs women in relation with 8 subscales

\begin{tabular}{lccccc}
\hline & $\begin{array}{c}\text { Mead } \\
\text { Women }\end{array}$ & Mead Men & $\begin{array}{c}\text { Mead } \\
\text { difference }\end{array}$ & T value & SIG \\
\hline Emotional Wellness (EW) * & 24.85 & 25.83 & -0.98 & -4.15 & 0.00 \\
Interpersonal relationships (IR) * & 30.76 & 31.66 & -0.90 & -2.87 & 0.00 \\
Material Wellness (MW) & 26.17 & 26.26 & -0.09 & -0.35 & 0.73 \\
Personal Development (PD) & 25.53 & 25.47 & 0.06 & 0.28 & 0.78 \\
Physical Wellness (BF) * & 24.67 & 25.79 & -1.12 & -4.86 & 0.00 \\
Autodetermination (AU) & 31.45 & 31.45 & 0.01 & 0.03 & 0.98 \\
Social inclusion (IS) * & 26.03 & 24.26 & 1.77 & 6.95 & 0.00 \\
Human Rights (HR) * & 32.24 & 31.49 & 0.75 & 2.62 & 0.01 \\
\hline
\end{tabular}

A T test was realized for independent samples to observe if there were significant differences between the sex groups. It was found that there were significant differences between men and women in five of the eight subscales. The men perceive a major emotional wellness, major interpersonal relationships, major physical wellness, while women perceive major inclusion that is social and human rights. 
Table 4. Comparative between men and women from the descendent media of the eight subscales

\begin{tabular}{llll}
\hline Men & Mead & Women & Mead \\
\hline Interpersonal Relationships (IR) * & 31.66 & Human Rights (HR) * & 32.24 \\
Human Rights (HR) * & 31.49 & Self-determination (SD) & 31.45 \\
Self-determination (SD) & 31.45 & Interpersonal Relationships (IR) * & 30.76 \\
Material Wellness (MW) & 26.26 & Material Wellness (MW) & 26.17 \\
Emotional Wellness (EW) * & 25.83 & Social Inclusion (IS) * & 26.03 \\
Physical Wellness (PW) * & 25.79 & Personal Development (PD) & 25.53 \\
Personal Development (PD) & 25.47 & Emotional Wellness (EW) * & 24.85 \\
Social inclusion (SI) * & 24.26 & Physical Wellness (PW) * & 24.67 \\
\hline
\end{tabular}

The last table shows the mead of each one of the eight subscales where the descendant order varies between men and women, while men perceive the human rights in higher degree. Women perceive that their physical wellness is less while men perceive in lesser extent social inclusion.

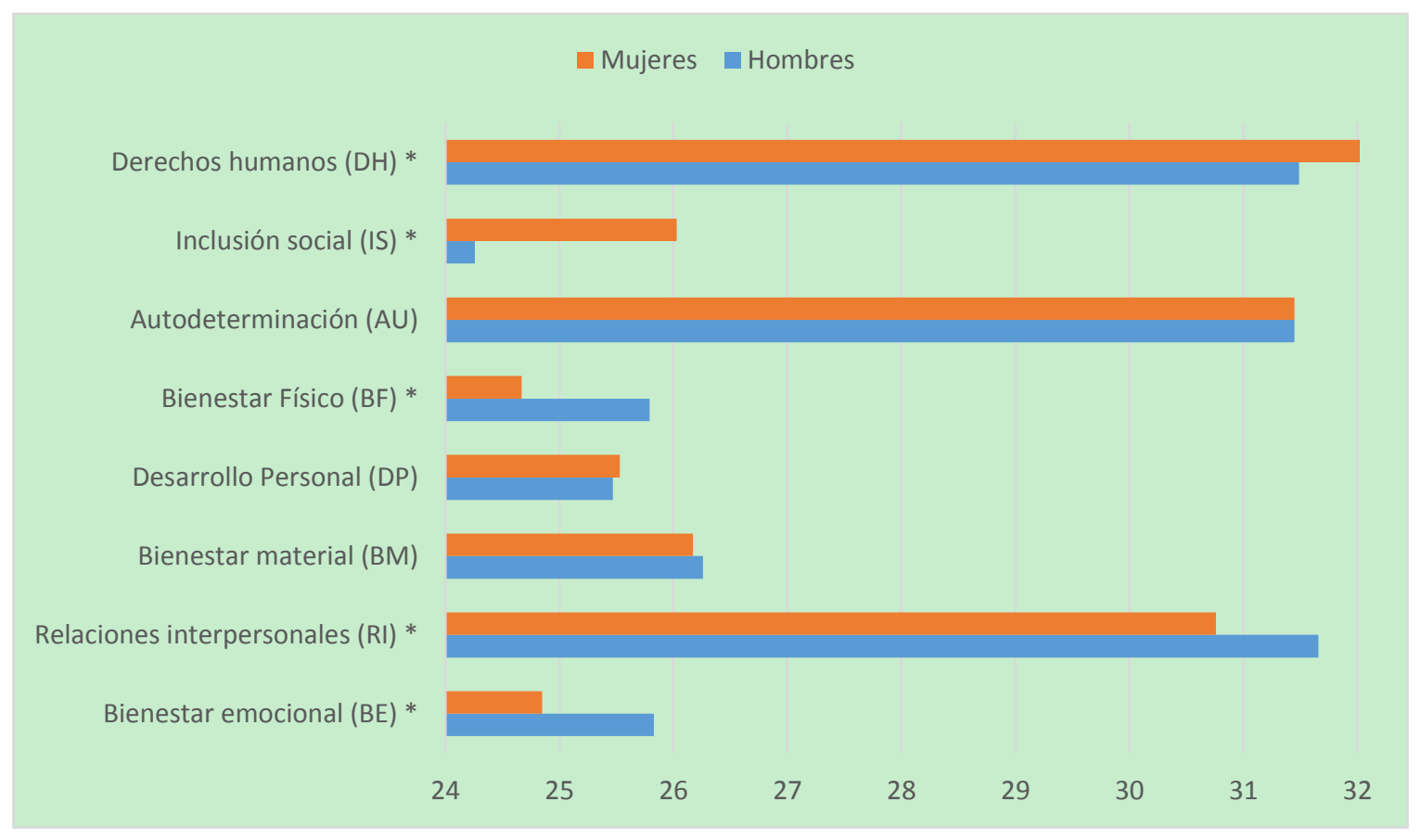

Figure 1. Perception between men and women

This chart shows from the bars of the eight subscales the perception between men and women. With high scores of the women about the quality of life in the dimensions of: Human rights, Social inclusion, Personal development. Self-determination is perceived on the same way. Men perceive in a higher way this dimensions of quality of life in: Physical wellness, Emotional wellness, Material wellness and Interpersonal relationships.

\section{Discussion}

After the analysis of Cronbach's alpha, it can be stablished that the questionnaire can be employ in young population in Mexico. That some changes can be made on the subscales of Physical wellness, social inclusion, material wellness, personal development to raise the internal reliability. However, in general, by the general score, is too high to validate the questionnaire. 
Quality of life in students, from eight factors, is perceived as good. External factors in greater values and on smaller the personal values.

Young people perception about their own life can be contradictory on personal factors; the young adult is facing a torment revolution inside him. Individualizes and even pathologies, the post-adolescent problems represent an exercise through which, to disassociate each case of their multideterminations, as Moral \& Ovejero (1999) say.

Young people perceive two spheres on the quality of life: the first one from the personal factors is perceived very low, while the second one, and from the social and external is perceived with very high values. In other words, to validate the quality of life, young people look at themselves as depersonalized with a high grade of support in the context, which matches with the description of Verdugo et al. (2013). They indicated that teenagers keep a higher mead of subjective wellness than young adults, and that the fronting style more used is the acceptance of responsibility, while the less used is the avoid escape.

Is good to highlight that young people, looking low scores of physical and emotional wellness, the personal development and the social inclusion, can be inferred as a negation of their own perception or better explained as depersonalization, based in the concept of micro system proposed by Schalock (2009) to explain the quality of life from the person's environment.

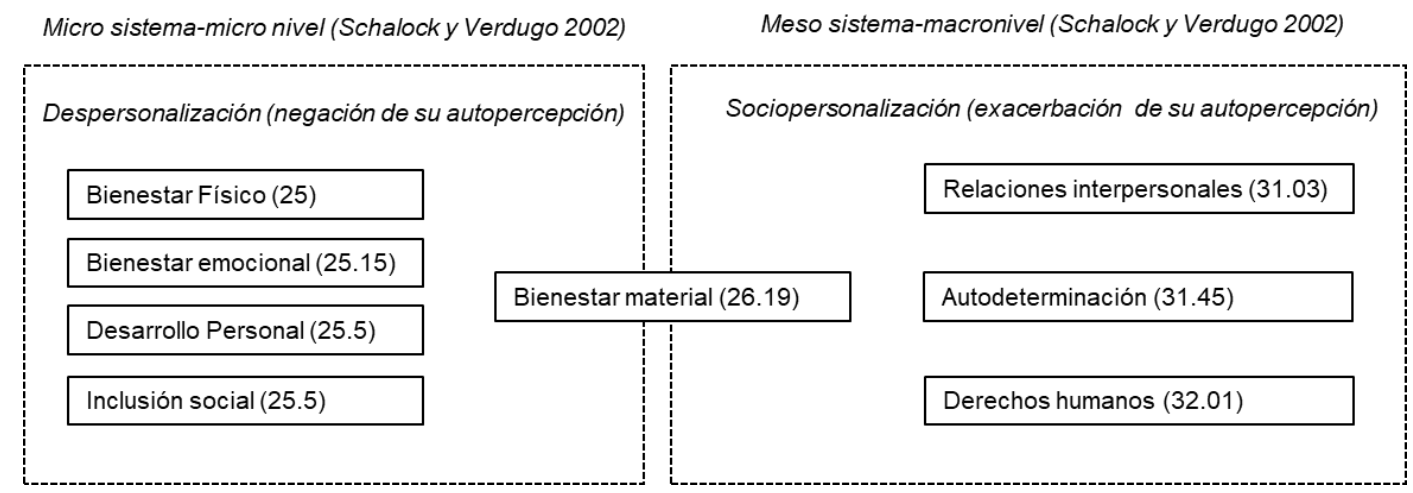

Figure 2. Explain the quality of life for Schalock

However, perceiving with a greater scores the factors of the context, such as interpersonal relationships, human rights and self-determination, the young people exacerbate their own perception explained as a socio-personalization with a strong relation of their context, in relation with the concept of Shalock of meso system.

In relation to the results of the comparative between men and women, significant differences were found in five of the eight subscales, where the physical and emotional wellness are different between them. This indicates that women have a less self-image or self-esteem than they mention it Yasuko, (2005).

In relation with the advancement of a genre equality world, women perceive a better social inclusion and greater human rights.

\section{References}

Calman, K. C. (1984). Quality of life in cancer patients - an hypothesis. Journal of medical ethics, 10(3), 124-127. https://doi.org/10.1136/jme.10.3.124

Castellón, A., \& Romero, V. (2004). Self-perception of quality of life. Gerontology Multidisciplinar Journal, 14(3), 131-137. Retrieved from: https://dialnet.unirioja.es/servlet/articulo?codigo=1032594

Cherepanov, D., Palta, M., Fryback, D. G., \& Robert, S. A. (2010). Gender differences in health-related quality-of-life are partly explained by sociodemographic and socioeconomic variation between adult men and women in the US: evidence from four US nationally representative data sets, Quality of Life Research, 19(8), 1115-1124. https://doi.org/10.1007/s11136-010-9673-x

George, D., \& Mallery, P. (2002). SPSS for Windows Step by Step A Simple Guide and reference, 11.0 update. Retrieved from https://www.amazon.co.uk/SPSS-Windows-Step-Simple-Reference/dp/0205375529

González, M. T., \& Landero, R. (2007, December). Emotional exhaustion scale for university students: Psicometric 
properties in Mexican sample. Anales de Psicología, 23(2), 253-257.

Guadarrama-Guadarrama, R., Hernández-Navor, J., Veytia López, M., \& Márquez Mendoza, O. (2014, December). Psychological Meaning of Quality of Life for Mexican Teenagers, 10(17). Retrieved from https://revistas.ucc.edu.co/index.php/pe/issue/view/93

Hörnquist, J. O. (1982). The concept of quality of life. Scandinavian Journal of Sciencie Medicine, 10, 57-61. https://doi.org/10.1177/140349488201000204

Hörnquist, J. O. (1990). Quality of Life: concept and assessment. Scandinavian Journal of Sciencie Medicin, 18, 69-79. https://doi.org/10.1177/140349489001800111

Leelakilthanit, O., \& Day, R. L. (1992). Quality of life in Thailand. Social Indicators Research, 27, 41-57. https://doi.org/10.1007/BF00300509

Li, L., Young, D., Wei, H., Zhang, Y., Zheng, Y., Xiao, S., Wang, X., \& Chen, X. (2010, March). The Relationship Between Objective Life Status and Subjective Life Satisfaction With Quality of Life. Behavioral medicine, 23(4). Retrieved from http://www.tandfonline.com/doi/abs/10.1080/08964289809596371

Moral, M., \& Ovejero, A. (1999). The delayed construction of the professional identity in young people. Psicothema, 11(1), 83-96. Retrieved from https://www.redalyc.org/articulo.oa?id=72711108

National Council for the evaluation of social development policy. (2012). Report of poverty in Mexico 2010: the country, its states and its municipalities. Retrieved from https://www.coneval.org.mx/Informes/Coordinacion/INFORMES_Y_PUBLICACIONES_PDF/REPORT_OF_ POVERTY_IN_MEXICO_2010.pdf

OECD. (2016). Education at a Glance 2016: OECD indicators. OECD Publishing, Paris. Retrieved from http://download.ei-ie.org/Docs/WebDepot/EaG2016_EN.pdf

Oppong, J., Ironside, R., \& Kennedy, L. (1988). Perceived quality of life in a centre-periphery framework. Social Indicators Research, 20(6), 605-620. Retrieved from http://www.jstor.org/stable/25427017

Shaw, A. (1977). Defining The Quality of Life. The Hastings Center Report, 7(5). https://doi.org/10.2307/3560715

Tarazona, D. (2005). Self-esteem, satisfaction with life and conditions of habitability in adolescents students of fifth year of average. A factorial study according to poverty and sex. Psicology Investigation Journal, 8(2). https://doi.org/10.15381/rinvp.v8i2.4048

Tuesca, R. (2005). Quality of life, its importance and how to measure it. Salud Uninorte, 21, 76-86.

Urzúa, A., \& Caqueo-Urízar, A. (2012). Quality of life: A theoretical review. Therapy psychological, 30(1), 61-71. Retrieved from https://www.redalyc.org/articulo.oa?id=78523000006

Urzúa, A., \& Mercado, G. (2008). Quality of life evaluation of teenagers trough Kiddo - Kindl. Therapy psychological, 26(1), 133-141.

Verdugo, M., Arias, B., Gómez, L., \& Schalock, R. (2009). Aplication manual for the GENCAT scale of quality of life. Retrieved from http://inico.usal.es/documentos/EscalaGencatManualCAST.pdf

Verdugo, M., Ponce de león, B., Guardado, R.., Meda, R., Uribe, J., \& Guzán, J. (2013). Styles of coping with stress and well-being subjective in adolescents and young people. Journal Latinoamerican of Sciences Social, 11(1), 79-91. Retrieved from http://www.scielo.org.co/pdf/rlcs/v11n1/v11n1a05.pdf

Yasuko, A., Romano, S., García, N., \& Félix, M. (2005, June). Indicatora of objective and subjctive of quality of life. Teaching and research in National Psychology, 10(1). Retrieved from http://www.redalyc.org/articulo.oa?id=29210106 